\title{
The Palynological Compass: A Case Study In Viticoideae (Vitex L.)
}

\author{
C. Cabral ${ }^{* * *}$, M. Möller ${ }^{* *}$ and F. Sales ${ }^{*, * *}$ \\ *Department of Botany, University, 3001-456 Coimbra, Portugal \\ ${ }^{* *}$ Royal Botanic Garden Edinburgh, Edinburgh EH3 5LR, U.K. \\ cmdscabral@gmail.com
}

The concept of palynological compass was introduced in 1969 by Erdtman [1] to express the way palynological evidence points to systematic relationships. Recent evidence shows that, in the cases studied, the palynological compass points to the same phylogenetic direction as the molecular data $[2,3]$.

Vitex is taxonomically complex comprising ca. 250 tropical, subtropical and a few temperate taxa with a pantropical distribution. Pieper revised a major part of the genus in 1928 [4], and divided it into five subgenera. Large \& Mabberley in 1995 published the first assessment of the palynology of Vitex which included 129 taxa [5]; the second palinological investigation was by De Vere on Malagasy species [6]. The African grex Pilosae (subgenus Vitex) was used in the present work as a case study to unravel the potential of pollen morphology as palynological compass in the Viticoideae.

Herbarium material was used, 3 accessions per species. Anthers were cleaned with a combination of acetone $70 \%$ and an ultrasonic bath for 12 min, sputter coated with palladium in an Emitech K575x sputter coater and observed under a LEO supra 55VP digital scanning electron microscope. Pollen morphology was compared with a well-supported phylogeny of the genus.

All pollen grains of the species analysed are 3-colpate; the shape is circular in polar view (figure 1, right), and circular or elliptic in equatorial view (figure 1, left). Although previous studies pointed to little variation in the pollen morphology [5-6], 5 pollen types of ornamentation were found in the species studied (figure 2): 4 types in grex Pilosae: reticulate (C), perforate (D), [7], reticulateretipilate (E) and spongy (B) and the type micro-perforate (A) [7] in the remaining African species studied for comparison. Plant material of the species with type E was not sequenced. A, B, C \& D pollen types of ornamentation were compared with the molecular phylogeny. The phylogenetic clades generated in the strict consensus tree (figure 3 ) were compared with these 4 pollen types.

The species of grex Pilosae under investigation appear in the phylogeny group in two distinct clades A \& B. The remaining Tropical African species form clade C; grex Pilosae and two other species ( $V . s p .5 \& V$. sp. 10) group in clade B. Pollen of the $\mathrm{S}$ American clade was not assessed. Pollen types C, A \& D matched the molecular phylogenetic clades A, C \& B (figure 3). All species included in clade A have reticulate pollen, except $V$. bogalensis, the only species in the phylogeny with spongy pollen; clade $\mathrm{B}$ has perforate pollen and clade $\mathrm{C}$ micro-perforate pollen.

As in other plant groups, such as Cactaceae and Campanulaceae [1,2], pollen morphology in grex Pilosae points to the same phylogenetic direction as the molecular data. 


\section{Acknowledgements}

We thank to Prof Dr David Kay Ferguson for provoking discussion and to FCT for funding support (SFRH/BD/12984/2003).

\section{References}

[1] G. Erdtman, Handbook of Palynology, Munksgaard, Copenhagen, 1969.

[2] S. Blackmore, in: B. Nordenstam, G. El-Ghazaly, M. Kassas (Eds.), Plant Systematics for the 21st Century, Portland Press, London, 2000, p. 161.

[3] S. Blackmore, Pl. Syst. Evol. 263 (2007) 3.

[4] W. Pieper, Bot. Jahrb. Syst. 62 (1928) 1.

[5] M.F. Large \& D.J. Mabberley, Grana 34(5) (1995) 291.

[6] N. De Vere, Systematics of the genus Vitex L. (Labiatae) in Madagascar, MSc thesis, 1997.

[7] W. Punt et al., Rev. Palaeobot. Palynol. 143 (2007) 1. 


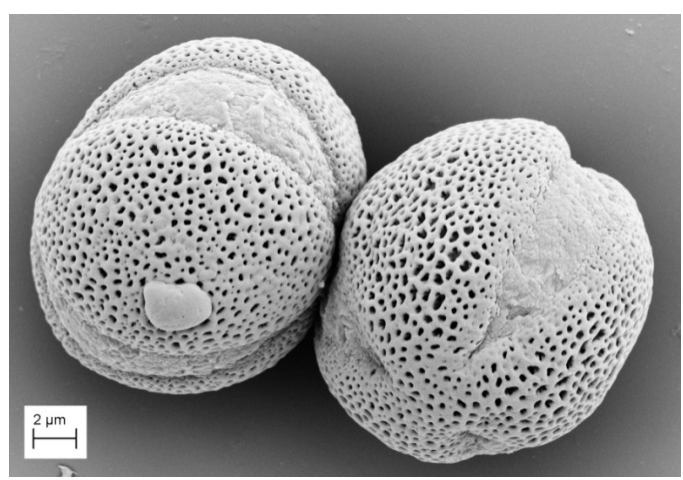

Figure 1. Photograph of equatorial and polar views, of pollen in Vitex, using scanning electron microscopy (SEM).
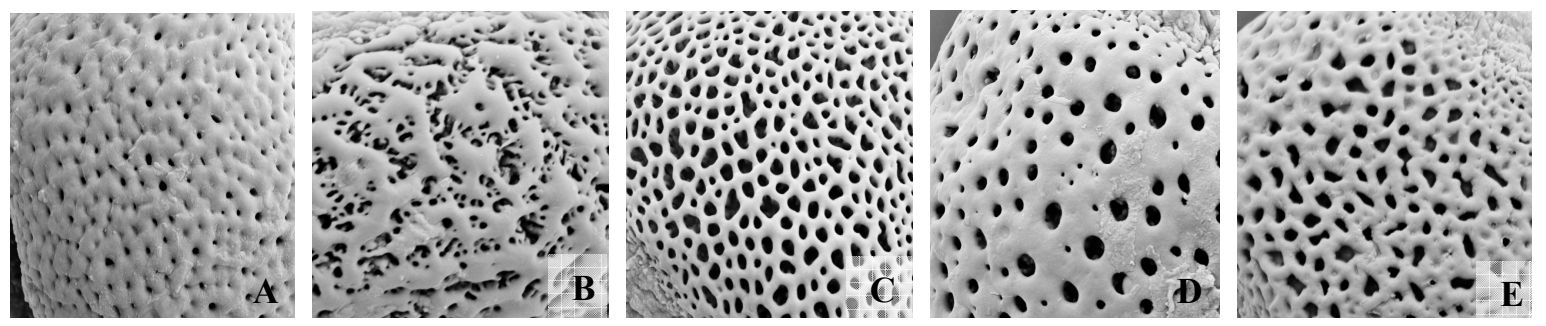

Figure 2. SEM photographs of the 5 pollen types found in the present investigation. A. microperforate; B. spongy; C. reticulate; D. perforate; and E. reticulate-retipilate. 


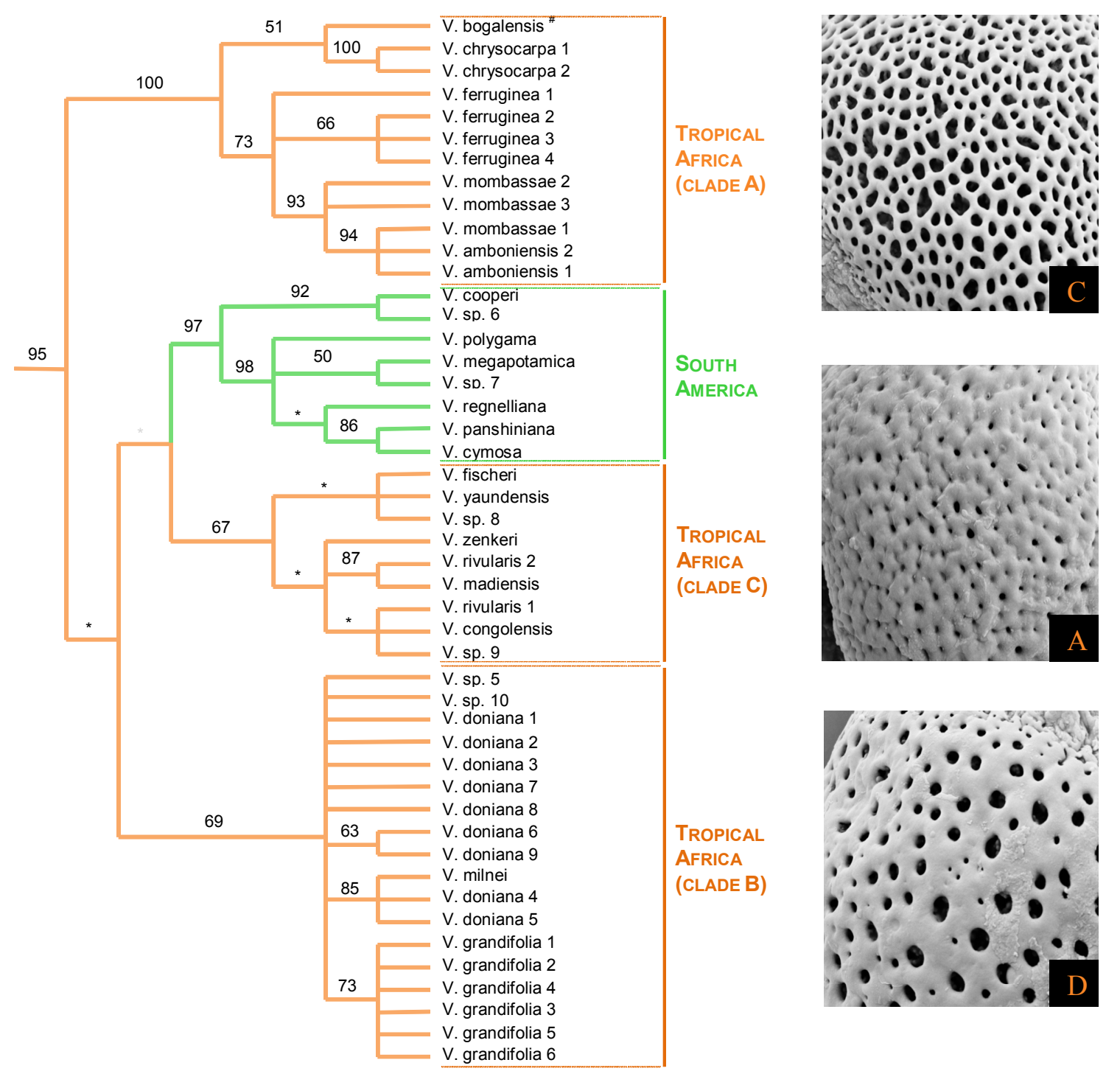

Figure 3. Pollen types (right) found in the species included in this part of the strict consensus tree of 36 most parsimonious trees based on nucleotide sequences plus gap characters after maximum parsimony analysis of Vitex ITS matrix. Numbers above branches indicate bootstrap support; *asterisks indicate bootstrap values $<50 \%$. ${ }^{\#} V$. bogalensis has spongy pollen (B). 